\title{
BLESSING IN DISGUISE: THE NEW DATE FOR THE ASLO ASM 2021 IN PALMA INCREASES OPTIONS FOR ENJOYING CULTURAL ACTIVITIES
}

Manuel Hidalgo, Lluís Gómez-Pujol, Nona Sheila R. Agawin, Eva Sintes, Iris E. Hendriks, Eva AlouFont, María Capa, Hilmar Hinz, Núria Marbà, and Marlene Wesselmann

\author{
Manuel Hidalgo, Instituto Español de Oceanografía (IEO), Centro Oceanográfico de Baleares, Ecosystem \\ Oceanography Group (GRECO), Palma, Spain; jm.hidalgo@ieo.es \\ Lluís Gómez-Pujol, Department of Biology, University of the Balearic Islands, Palma, Spain \\ Nona Sheila R. Agawin, Department of Biology, University of the Balearic Islands, Palma, Spain; \\ nona.agawin@uib.es \\ Eva Sintes, Instituto Español de Oceanografía (IEO), Centro Oceanográfico de Baleares, Palma, \\ Spain \\ Iris E. Hendriks, Mediterranean Institute for Advanced Studies (IMEDEA, CSIC-UIB), \\ Esporles, Spain \\ Eva Alou-Font, Balearic Islands Coastal Observing and Forecasting System, Palma, Spain \\ María Capa, Department of Biology, University of the Balearic Islands, Palma, Spain \\ Hilmar Hinz, Mediterranean Institute for Advanced Studies (IMEDEA, CSIC-UIB), Esporles, Spain \\ Núria Marbà, Mediterranean Institute for Advanced Studies (IMEDEA, CSIC-UIB), \\ Esporles, Spain \\ Marlene Wesselmann, Mediterranean Institute for Advanced Studies (IMEDEA, CSIC-UIB), Esporles, Spain
}

The current global situation caused by the COVID-19 pandemic has triggered changes in most scientific meetings worldwide. The ASLO 2021 in Palma "Aquatic Sciences for a sustainable future: nurturing cooperation", has also been re-scheduled to June 22-27. As "blessing in disguise", this change from a winter to a summer meeting increases the options of enjoying cultural opportunities in Mallorca. Here we describe in a nutshell the most relevant options to experience during the sunny season of this unique Mediterranean Island.

Madame A. L. Aurore Dupin, best known by her pen name George Sand, was one of the most notable writers of the European Romantic era who stayed in Mallorca for a year (1838-1839) with her lover, the famous musician Frédéric Chopin. George Sand described the island in her words: "It is the Green Helvetia, under the sky of Calabria, with the solemnity and silence of the East". Mallorca has numerous small towns and villages where one can experience the charm of stepping back in time as George Sand did. The most picturesque villages, framed in a magnificent landscape, are Banyalbufar, Valldemossa, Deià, Fornalutx, Alcúdia or Artà, most of them located in the Serra de 
Tramuntana, the island's major mountain range and UNESCO World Heritage site. Every town and village in the island has a regular weekly market where it is well worth to lose oneself amidst the stalls to find the best local products and handicrafts. Sineu, Santanyí, and Artà have some of the most interesting markets, whereas visiting the indoor Mercat de l'Olivar and Santa Catalina's covered city markets in Palma city is a must.

Discovering Mallorca's countryside brings also other opportunities like the 'Navetas'-and 'Talayots', which are mysterious monuments built with big rocks as far as than 4.000 years ago (Bronze and Iron ages) by the first inhabitants of the island. This old civilization developed an architectural culture, known as Talaiotic, with some cultural parallelisms and references in Corsica and Sardinia (Fig. 1). There are over 500 archeological sites spread between the islands of Mallorca and Menorca. Mallorca island is also rich in Roman antiques and Muslim heritage. In 1229, it was incorporated in the Christian Kingdom of Aragon, and despite the fact that since de middle ages the native language and culture of the Balearic Islands is Catalan, historically, the Islands are also a cross point of maritime routes, cultures and languages that have enriched and promoted the culture and the islanders' hospitality.

Summer in Mallorca provides the opportunity to enjoy many different international music festivals, in addition to other outdoor cultural events and theater performances. Most towns and villages hold their main festivities (so called 'Festes') in summer, where you can enjoy the rich folklore of Mallorca characterized by melodious music and ceremonial ancestral pagan fertility dances, such as "cossiers" from Algaida, Montuïri, Pollença or Alaró among others. Traditional unique music instruments, such as the 'xeremies' (a sort of bagpipe), are often played together with a 'flabiol' and 'tamborino' (small flute and drum). Improvised, energetic and free steps dances, known as "ball de bot", where women govern the dance and men should follow them reminding 
a courtship ritual, are at the essence of Mallorca's traditional dancing (Fig. 2). 'Rondaies' (traditional folk tales of Mallorca, which were passed on orally from the parents to their children) are also one of the great treasures of the island with a broad catalogue of more than 420 tales.

Last but not least, discovering the old town of Palma, the capital of the island, is also a must to breathe in the past and current Mallorcan culture. The old town of Palma has impressive architectural monuments such as the Gothic Roman Cathedral, built during Jaume II's reign and holding the second highest nave of all Gothic cathedrals in the world. The Cathedral has an exciting historical art collection, with the contemporary contribution at the chapel of 'Sant Pere' by Miquel Barceló and other areas refurbished by the famous architect Antonio Gaudí. Another iconic architectural building in Palma is 'La Llotja' (the commerce hall), one of the few Gothic civil buildings in Spain. The Bellver Castle is also a striking landmark that offers panoramic views overlooking the city of Palma and its Bay. It functioned as a royal fortress, summer residence and even as a prison, and nowadays accommodates the history museum of the city. Finally, among the broad list of world-famous museums in Palma, 'Fundació Juan March Contemporary Art Museum', 'Fundació Miró' and 'Es Baluard' Museum of Modern \& Contemporary Art stand out; the latter is an impressive contemporary building located near the old city walls that houses a large collection of modern art.

Summing up, Mallorca's historically rich cultural tradition and non-material heritage mingling with international and contemporary art and music vanguards are ready for you to experience in the next ASLO 2021 summer meeting! 


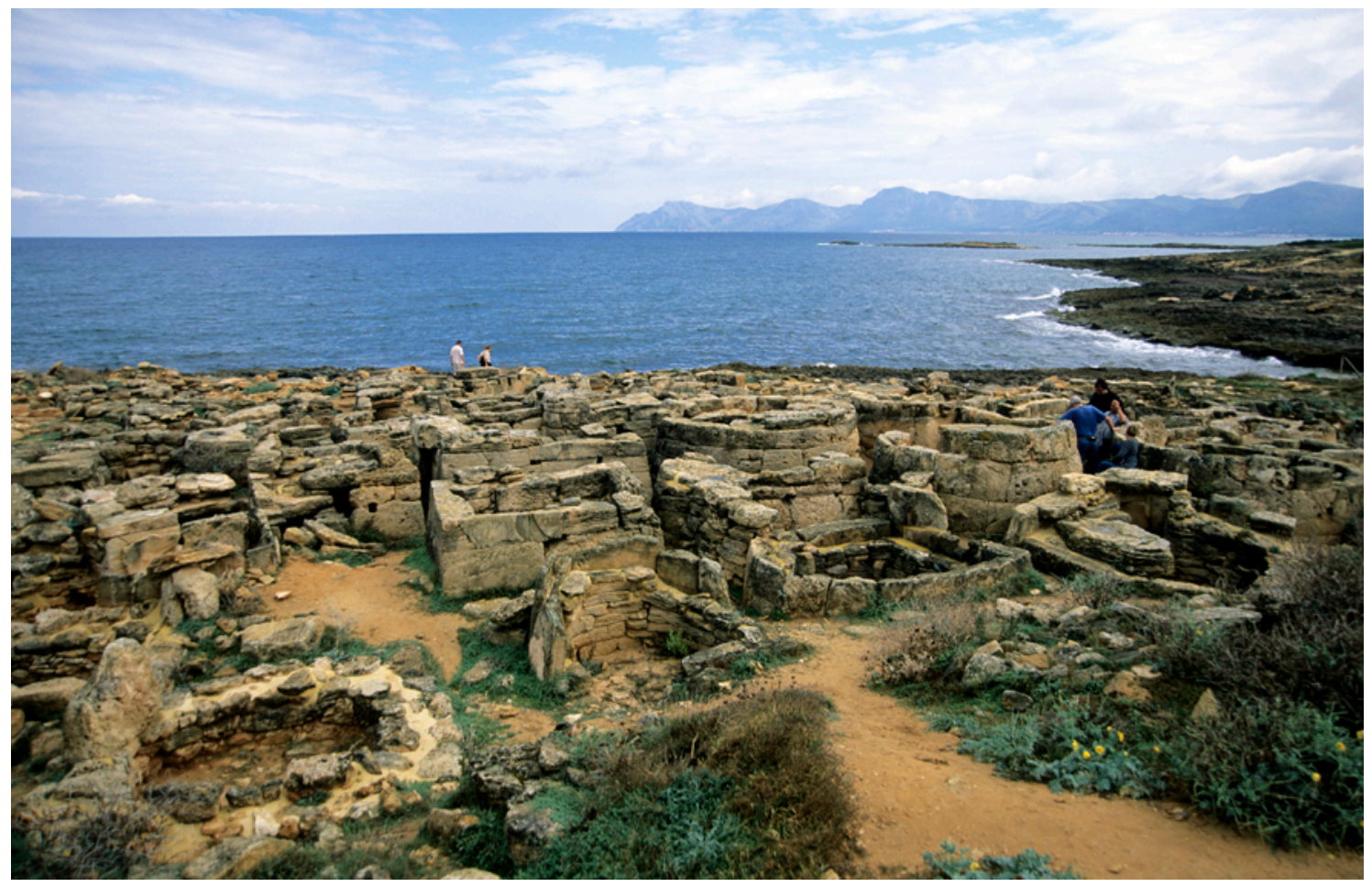

Fig. 1. The Talaiotic necropolis of Son Real. Photo by Eduardo Miralles, provided by Govern de les Illes Balears, Agència d'Estratègia Turística de les Illes Balears (AETIB).

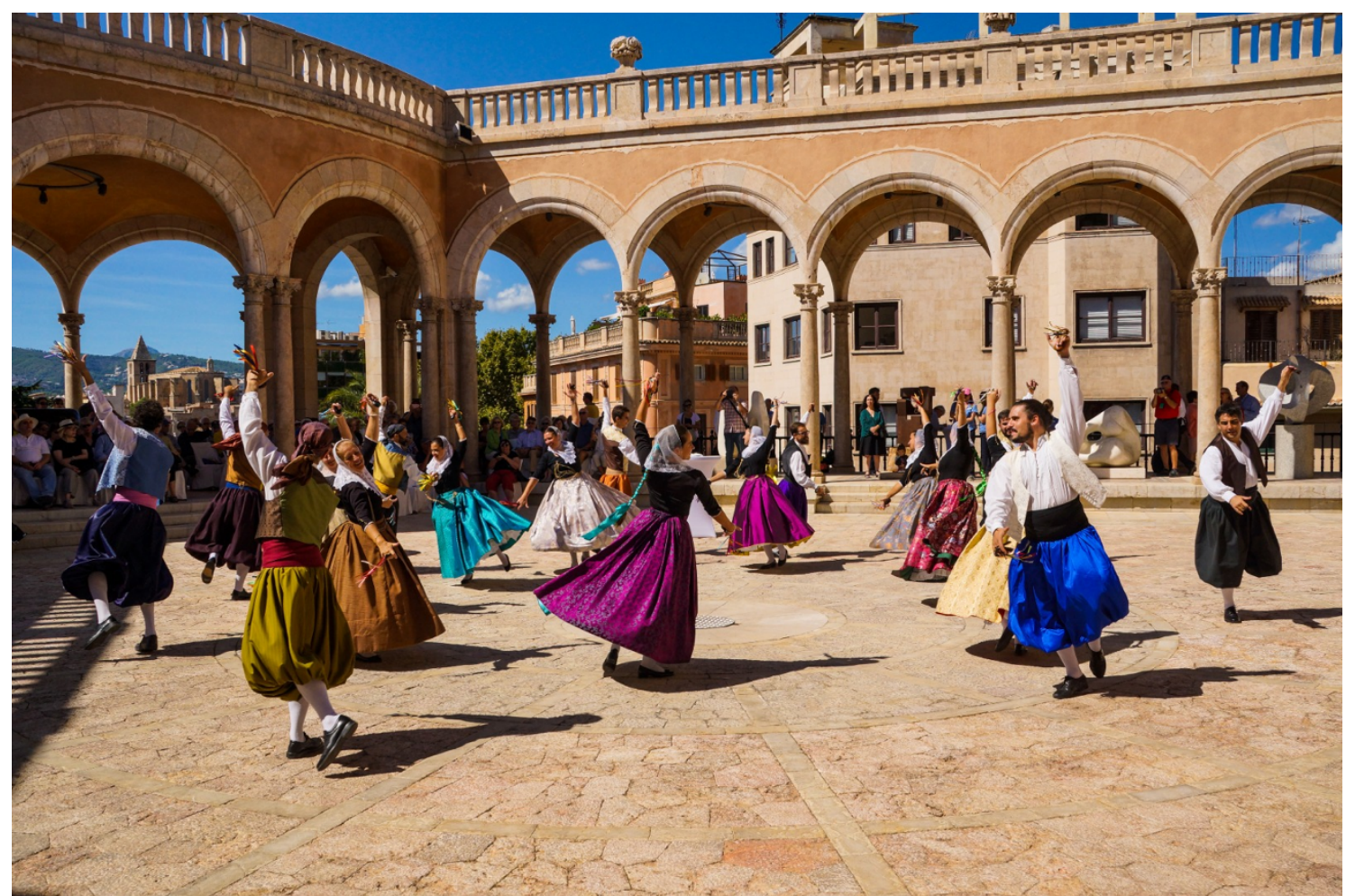

Fig. 2. Traditional Mallorcan dances known as "ball de bot". Photo by Lluís Bordils, provided by Lluís Gómez-Pujol. 